\title{
ANALISIS DAN PEMODELAN POSISI ACCESS POINT PADA JARINGAN WI-FI MENGGUNAKAN METODE SIMULATE ANNEALING
}

\author{
Anjar Wanto, Jaya T. Hardinata, Herlan F Silaban, Widodo Saputra \\ Mahasiswa Magister Fasilkom TI USU, Fasilkom TI USU \\ Jalan Dr. T. Mansur No. 9, Kampus Padang Bulan, Medan, 20155, Sumatera Utara \\ anjarwanto@gmail.com, jayatatahardinata@gmail.com, herlan76ban@gmail.com , \\ widodosaputra01@gmail.com
}

\begin{abstract}
Laying the position of the access point on the Wi-Fi network in a room is needed to optimize the signal strength received from the transmitter to the receiver. The parameters that determine the performance of the access point is the value of the signal strength. Strong or weak a signal access point will be affected by distance and barriers that exist between the access point and a client that accesses the access point. This study has been performed several simulations in multiple rooms are placed the access point to the receiver. The parameters used to measure the signal strength using inSSIDer applications that generate value RSSI (Received Signal Strength Indication) of a transmitter to the receiver and barriers (barriers) that may influence the strength of the signal. From this research strength of the signal received by the receiver not only in pengaruhui by the distance between accespoint to the recipient, but rather influenced by barriers (barriers) which is in a room. From the results of the research are expected to be able to obtain appropriate modeling to optimize access point placement position using the Simulate annealing method.
\end{abstract}

Keyword: WI-FI, converage Area, Signals, Simulate Annealing

\begin{abstract}
Abstrak
Peletakan posisi access point pada jaringan WI-FI dalam suatu ruangan sangat diperlukan untuk mengoptimalkan kekuatan sinyal yang diterima dari transmitter terhadap receiver. Parameter yang menentukan performa access point adalah nilai kekuatan sinyal. Kuat atau lemahnya sebuah sinyal access point akan dipengaruhi jarak dan penghalang yang ada antara access point dan client yang mengakses access point tersebut. Pada penelitian ini telah dilakukan beberapa simulasi di beberapa ruangan yang diletakan access point terhadap receiver. Parameter yang di gunakan untuk pengukuran kekuatan sinyal menggunakan aplikasi inSSIDer yang menghasilkan nilai RSSI (Received Signal Strength Indication) dari sebuah transmitter terhadap receiver dan penghalang (hambatan) yang dapat mempengarui kekuatan sinyal tersebut. Dari penelitian ini kekuatan sinyal yang di terima oleh receiver tidak hanya di pengaruhui oleh jarak antara accespoint terhadap penerima, melainkan di pengaruhi oleh penghalang(hambatan) yang ada pada suatu ruangan. Dari hasil penelitain ini diharapkan dapat memperoleh
\end{abstract}


pemodelan yang sesuai untuk mengoptimalkan peletakan posisi acces point dengan menggunakan metode simulate annealing.

Kata Kunci : WI-FI, Converage Area, Sinyal, Simulate Annealing

\section{PENDAHULUAN}

Dalam mengakses layanan internet, sering kali diperoleh adanya sinyalsinyal yang bertumpukan pada suatu area, sementara itu di lain area tidak terdapat sinyal sama sekali (area blankspot). Oleh karena itu, penempatan access point yang tepat agar bisa optimal semua pengguna di area tersebut bisa menikmati layanan internet. Penempatan access point merupakan salah satu permasalahan di bidang infrastrukturjaringan, di karenakan penempatan access point secara optimal diperlukan pertimbangan dan analisa teoritis sebelum diimplementasikan. Beragam faktor antara lain kekuatan sinyal access point, desain dan infrastruktur ruangan, sebaran pengguna access point yang berkelompok, terjadinya interferensi gelombang radio, hambatan sinyal seperti frekuensi radio, dan penghalang yang dapat menimbulkan gangguan terhadap penerimaan sinyal dari access point (transmitter) terhadap perangkat penerima (receiver). Posisi access point sangat berpengaruh terhadap area tercoveruntuk penerima pada sebuah jaringan Wi-Fi. Semakin optimal penempatan posisi access point, semakin optimal juga area tercover untuk penerima.

Oleh karena itu, menempatkan access point dengan cara manual tentunya akan membutuhkan tenaga yang lebih untuk melakukan survey pengukuran di lapangan, waktu yang lama dan biaya yang tidak murah. Untuk itu dibutuhkan penanganan dan mekanisme yang baik dalam meminimalisir tenaga, biaya dan waktu seorang perencana jaringan Wi-Fi dalam menempatkan access pointpada tempat yang optimal sehingga cakupan area yang dihasilkan lebih optimal serta dapat menentukan jumlah access point yang ideal untuk suatu lokasi dengan berbagai ukuran yang ada yang dapat ditentukan melalui perhitungan tanpa melakukan survei lapangan yang aktual.

Ketertarikan peneliti untuk melakukan penelitian ini disebabkan karena peneliti bermaksud akan melakukan optimisasi terhadap access point pada jaringan Wi-Fi. Hasil penelitian memperlihatkan cara untuk menentukan coverage area maksimum dengan metode Simulate Annealing berdasarkan fungsi jarak dari hasil pengukuran di lapangan. Dari penelitian tersebut dapat disimpulkan bahwa berdasarkan hasil pengukuran dapat diketahui bahwa level daya terima berbanding terbalik dengan jarak antara pemancar (Tx) dan penerima (Rx), semakin jauh jarak antara pemancar (Tx) dan penerima (Rx) maka level daya terima semakin kecil. Penelitian memperlihatkan cara untuk menentukan coverage area maksimum dengan algoritma genetika melalui perhitungan parameter yang dicari untuk menentukan fungsi fitness dari algoritma genetika berdasarkan fungsi jarak dari hasil pengukuran di lapangan. Dari penelitian tersebut dapat disimpulkan bahwa level daya terima berbanding terbalik dengan jarak antara pemancar (Tx) dengan penerima (Rx); semakin jauh jarak antar pemancar (Tx) dan penerima (Rx) maka level daya terima semakin kecil. Hasil penelitian menunjukkan bahwa alokasi fungsi obyektif didasarkan pada rata-rata minimal 
pathlost yang diterima dari seluruh desain area dan maksimum pathloss yang diterima kepada penerima. Model yang dijelaskan tersebut dapat digunakan untuk mencari penempatan optimal access point yang mengcover pengguna sebanyak mungkin, dengan pendekatan Simulasi Annealing. Dalam penelitian tersebut dibahas salah satu penerapan dari simulasi bersyarat (conditional simulation). Hasil penelitian adalah tentang kinerja algoritma simulate annealing pada peletakan lokasi (lokalisasi) peletakan posisi access point Wi-Fi. Pada penelitian ini, parameter yang digunakan adalah fungsi jarak dan RSS (Received Signal Strength).

Oleh karena itu, sebuah pendekatan alternatif yang diusulkan peneliti adalah membuat pemodelan menggunakan perangkat lunak menggunakan metode optimisasi yang memberikan solusi yang lebih "bagus" tanpa melebihi batasan waktu yang disediakan. Solusi yang "bagus" belum tentu yang paling optimum (global optimum) tetapi sudah dapat diterima oleh user. Metode optimisasi yang akan digunakan pada penelitian ini adalah Simulated Annealing yang merupakan metode optimisasi yang mensimulasikan proses annealing pada penempatan posisi access point untuk menghasilkan area tercover optimal dengan menggunakan energi seminimal mungkin.

\section{METODE PENELITIAN}

\subsection{Lokasi Penelitian dan Waktu Penelitian}

Penelitian ini dilaksanakan di lingkungan gedung AMIK Tunas Bangsa Pematangsiantar. Pengambilan titik sample di gedung I Lantai 4 AMIK Tunas Bangsa meliputi 5 Ruangan belajar mengajar yang masing-masing ruangan di batasin dengan dinding yang terbuat dari kayu.

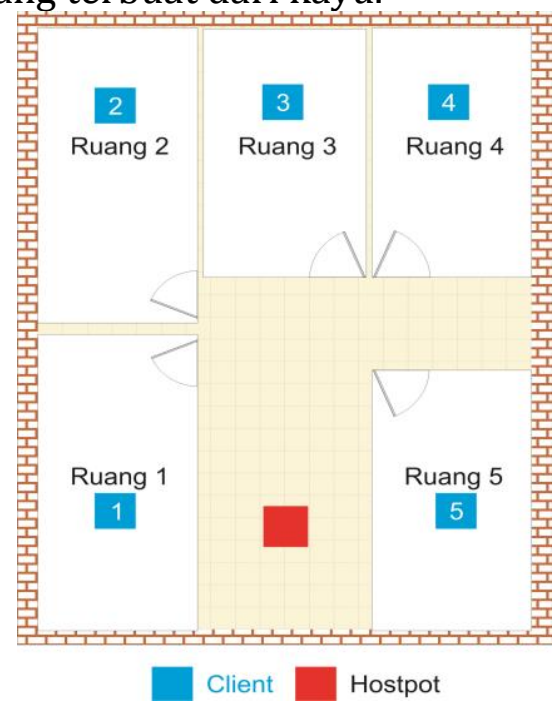

Gambar 1. Pengambilan sampel di Gedung I lantai 4 AMIK Tunas Bangsa Pematangsiantar

\subsection{Alat dan Bahan}

\subsubsection{Alat}

a. Access Point

Alat ini berfungsi sebagai transmitter yang memancarkan sinyal gelombang radio. 
b. Netbook/Handphone

Alat ini berfungsi sebagai receiver yang menerima pancaran sinyal gelombang radio darisebuah atau beberapa access point.

\subsubsection{Bahan}
a. Bahan yang digunakan dalam penelitian ini berupa:
InSSIDER. InSSIDER berfungsi sebagai software aplikasi gratis yang digunakan untuk scanning jaringan Wi-Fi dengan parameter utama SSID dan dapat melacak kekuatan sinyal dari waktu ke waktu serta menentukan pengaturan keamanan, yang dipasang pada Netbook ASUS Eee PC dengan Sistem Operasi Windows 7.
b. Kabel UTP
Digunakan untuk menghubungkan antara repeater dan access point.
c. Meteran
Meteran digunakan untuk mengukur ketinggian access point yang terpasang dan ketinggian receiver.

\subsection{Prosedur dan Pengumpulan Data}

\subsubsection{Prosedur}

Prosedur penelitian yang dilakukan oleh peneliti adalah:

a. Menyiapkan alat dan bahan.

b. Melakukan verifikasi perangkat Wi-Fi (Access Point) dengan cara melakukan setting IP address receiver dan pastikan IP address satu jaringan dengan IP address access point.

c. Cek koneksi terhadap access point dengan receiver.

d. Menginstal aplikasi InSSIDER berbasis Sistem Operasi Windows 8 yang digunakan untuk mengukur kekuatan sinyal Wi-Fi.

e. Menjalankan aplikasi InSSIDER untuk melakukan scanning Wi-Fi secara otomatis untuk melihat operasi access point yang berada di sekitarnya sehingga menghasilkan nilai RSSI (Received Signal Strength Indication).

\subsubsection{Teknik Pengumpulan Data}

a. Melakukan perencanaan penelitian yang membahas mengenai data yang akan diambil pada saat penelitian meliputi denah, tinggi access point, koordinat, jarak, RSSI dan propagasi.

b. Menentukan koordinat posisi Access Point dan posisi receiver pada propagasi LOS (Line Of Sight) dan NLOS (Non Line Of Sight).

c. Aplikasi inSSIDER yang telah dijalankan akan melaporkan data terhadap nilai RSSI yang diterima oleh receiver.

d. Pengumpulan data selesai.

\section{HASII DAN PEMBAHASAN}

\subsection{Metode}

Metode yang digunakan adalah simulate annealing. Penghitungan terhadap parameter-parameter yang dicari yaitu menentukan fungsi evaluasi atau fungsi objektif dari simulate annealing yang dihasilkan dari fungsi jarak, penghalang, ketinggian transmitter, pengguna, tipe dan merk access point dari hasil 
pengukuran di lapangan dan melakukan pengujian terhadap 1 (dua) buah perangkat access point yang diletakkan dalam ruang 1 (satu) dimensi dengan sistem propagasi Line OfSight (LOS) dan Non Line Of Sight (NLOS).

\subsection{Pemodelan Sistem Berdasarkan Kondisi Access Point Sebenarnya}

Pada pemodelan yang berdasarkan posisi access point sebenarnya, pemodelan dikelompokkan berdasarkan propagasinya yaitu Line OfSight (LOS) dan Non Line of Sight (NLOS). Pemodelan posisi access pointnya adalah membagi ruangan sesuai dengan gambar yang ruangan tersebut, dimana :

a. Menentukan perhitungan koordinat yang diawali dari bagian kiri atas ruang $1(0,0)$. Selanjutnya pertambahan nilai koordinat sumbu X adalah ke kanan dan pertambahan koordinat sumbu $Y$ adalah ke bawah.

b. Menentukan ketinggian transmitter yang dibagi kedalam tiga jenis ukuran ketinggian yaituketinggian $50 \mathrm{~cm}, 120 \mathrm{~cm}$ dan $330 \mathrm{~cm}$.

c. Menentukan titik koordinat transmitter ke-1 dengan posisi sebenarnya yang berada pada ruangan.

d. Mengukur besarnya RSSI (Received Signal Strength Indication) dari sesuai bertambahnya jauhnya jarak antara koordinat kedua transmitter dan koordinat receiver dengan bantuan aplikasi inSSIDER dengan propagasi LOS (Line Of Sight) dan NLOS (Non Line Of Sight).

e. Menghitung jarak antara titik koordinat transmitter dengan titik koordinat receiver menggunakan rumus matematis pada persamaan (1), yaitu metode Euclidean:

$$
d=\sqrt{(x 1-x 2)^{2}+(y 1-y 2)^{2}}
$$

f. Menentukan batasan nilai range dimana range adalah batasan sinyal yang menjadi ukuran sebuah area dalam skala yang dinyatakan tercover atau tidak tercover oleh sinyal yang dipancarkan access point (transmitter). Untuk menghitung nilai range diperoleh rumus pada persamaan (2):

$$
\text { Range }=\frac{s}{\text { skala ruang }}
$$

Dimana Range memiliki satuan pixel, $S$ adalah jarak threshold dan skala ruang $=30 \mathrm{~cm}$, jarak threshold diperoleh dari persamaan rumus (3):

$$
S=\frac{T h x \operatorname{SMax}}{P \min }
$$

Dimana Th adalah threshold level daya $=-30 \mathrm{dBm}$, Smax merupakan jarak maksimal hasil pengukuran (dalam satuan $\mathrm{m}$ ) dan Pmin adalah daya minimum hasil pengukuran. Sesuai dengan hasil penelitian, didapatkan data-data sebagai berikut : 


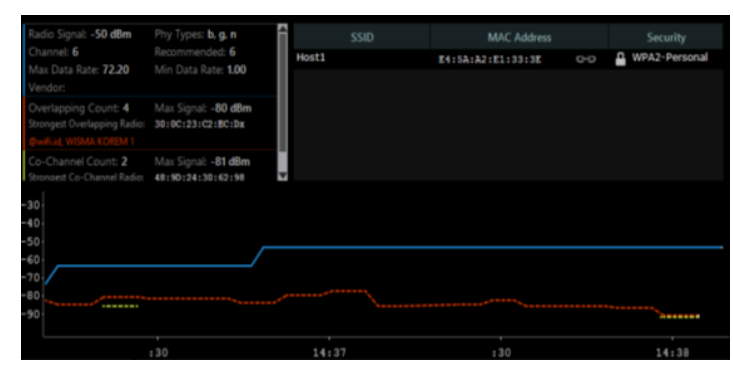

Gambar 2. Hasil Yang di dapat pada client 1 pada ruangan 1

Pada gambar 2. Dihasilkan radio signal yang di hasilkan oleh inssider ratarata menghasilkan RSSI $-50 \mathrm{dBm}$, jumlah penghambat (Overlapping Count) 4.

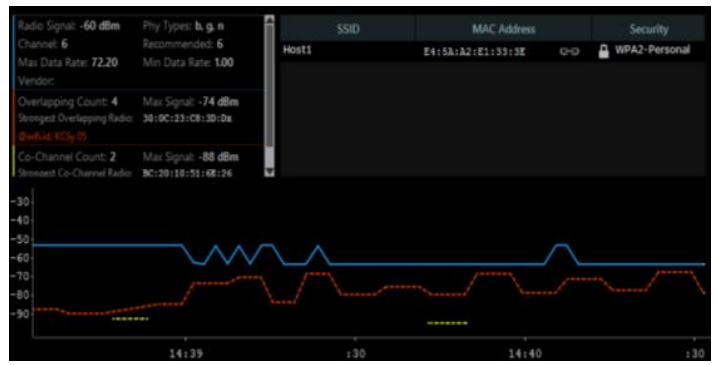

Gambar 3. Hasil Yang di dapat pada client 2 pada ruangan 2

Pada gambar 3. Dihasilkan radio signal yang di hasilkan oleh inssider ratarata menghasilkan RSSI -60 dBm di karenakan jarak antara accesPoint dan receiver lebih jauh dari client 1 walaupun jumlah penghambat (Overlapping Count) 4.

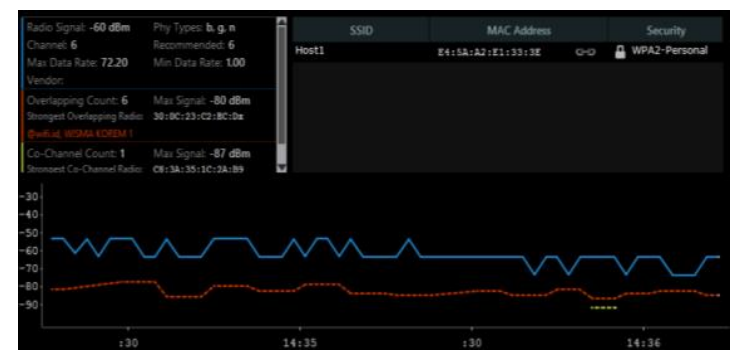

Gambar 4. Hasil Yang di dapat pada client 3 pada ruangan 3

Pada gambar 4. Dihasilkan radio signal yang di hasilkan oleh inssider ratarata menghasilkan RSSI -60 dBm di karenakan jarak antara acces point dan receiver lebih dekat dari client 2 tetapi jumlah penghambat (Overlapping Count) 6, tenyata hambatan mempengharui kekuatan sinyal.

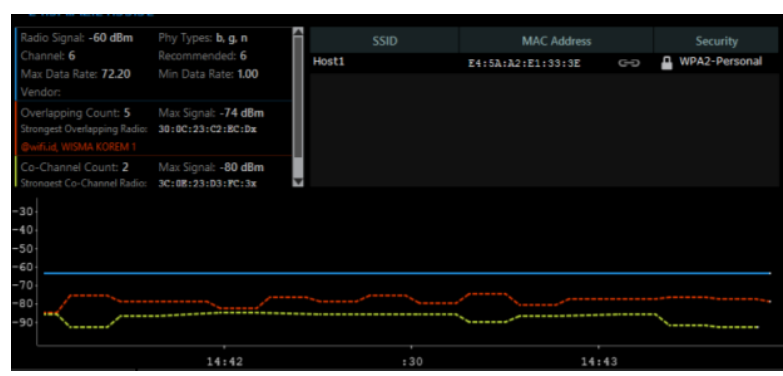

Gambar 5. Hasil Yang di dapat pada client 4 pada ruangan 4 
Pada gambar 5. Dihasilkan radio signal yang di hasilkan oleh inssider ratarata menghasilkan RSSI -60 dBm jarak antara acces point dan receiver lebih jauh dari client 3 tetapi jumlah penghambat (Overlapping Count) 5, sehingga kekuatan sinyal yang dihasilkan sama dengan client 3 dan client 2.

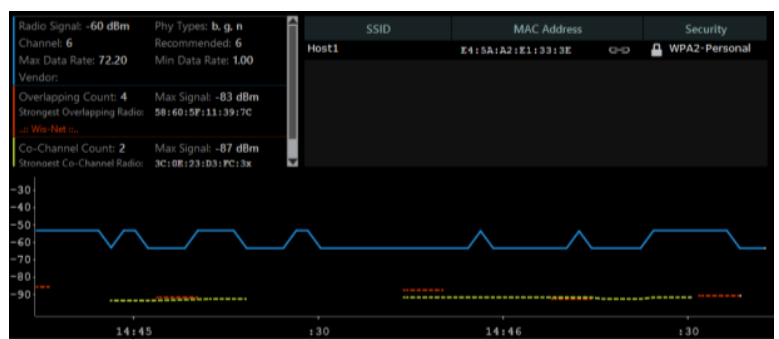

Gambar 6. Hasil Yang di dapat pada client 5 pada ruangan

Pada gambar 6. Dihasilkan radio signal yang di hasilkan oleh inssider ratarata menghasilkan RSSI $-60 \mathrm{dBm}$ di jarak antara acces point dan receiver lebih jauh dari client 1 tetapi jumlah penghambat (Overlapping Count) 4, tetapi menghasilkan kekuatan sinyal yang lebih rendah dari client 1 di karekan pada client 5 batas dinding menggunakan beton.

\subsection{Pemodelan Sistem Berdasarkan Metode Simulated Annealing}

Pada pemodelan menggunakan Simulated Annealing, akan dikembangkan sebuah model implementasi metode simulate annealing untuk penempatan 2 (dua) posisi access point menggunakan interferensi. Ada beberapa hal yang harus dirancang dalam menerapkan metode simulatedannealing yaitu fungsi objectif (costfunction), mekanisme inisialisasi solusi awal dan pembuatan solusi baru, skema pendinginan (cooling schedule) dan penetapan balasan terhadap output yang dikehendaki. Tiap hal tersebut akan diuraikan pada bagian-bagian berikut ini:

a. Inisialisasi Awal dan Mekanisme Pembuatan Solusi Baru

Pada penelitian ini, solusi awal untuk formasi penempatan access point diinisialisasi secara acak dengan cara membagi access point secara acak kedalam koordinat-koordinat yang terdapat pada area penelitian, koordinat ini didapat berdasarkan jumlah ubin dalam ruang penelitian dimana koordinat panjang (koordinat $\mathrm{x}$ ) dan koordinat lebar (koordinat y) dan setiap access point akan mengalokasikan kepada receiver nilai RSSI yang baru pada koordinat tertentu yang telah ditetapkan sehingga diperoleh perubahan jarak antara acess point dan receiver, kemudian akan dihitung nilai range yang baru untuk menghasilkan nilai area tercover optimal. Mekanisme yang digunakan untuk membangkitkan solusi baru adalah pilih access point secara acak terhadap koordinat sebagai tempat posisi access pointyang baru, yang bukan merupakan koordinat yang ditempati sebelumnya, kemudian setiap access point akan mengalokasikan kepada receiver dengan nilai RSSI yang baru sesuai dengan perubahan jarak.

b. Proses Iterasi

Proses iterasi dilakukan untuk mencari nilai nilai area tercover paling optimal dimana proses iterasinya dilakukan dengan metode pencarian acak tanpa nilai target, pencarian dilakukan hingga diperoleh nilai tertinggi, karena tanpa nilai target maka solusi saat ini selalu dibandingkan dengan 
nilai sebelumnya untuk menunjukkan tingkat akurasi dari nilai solusi. Berdasarkan uraian di atas, akan dikembangkan sebuah pemodelan menggunakan metode simulate annealing pada penempatan posisi access point seperti ditunjukkan pada Gambar berikut :

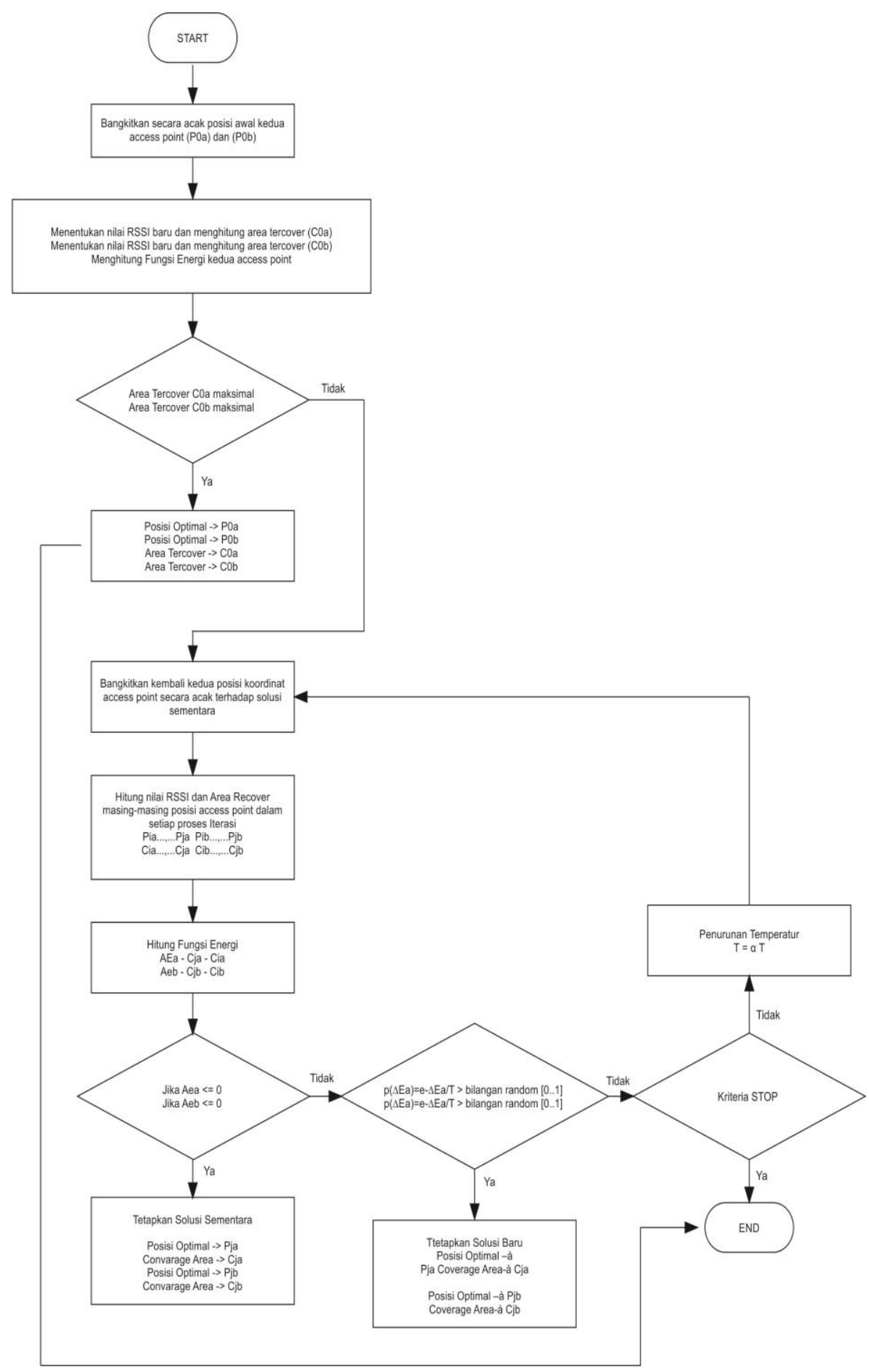

Gambar 7. Flowchartpemodelan penempatan posisi Access Pointdengan interferensi menggunakan Simulated Annealing 


\subsection{Hasil}

Pada bagian ini akan dijelaskan mengenai serangkaian pengujian dan evaluasi terhadap metode yang digunakan. Pengujian dilakukan untuk mengetahui kinerja terhadap metode yang dihasilkan dari proses implementasi. Kriteria sinyal yang di hasilkan dapat di lihat pada tabel di bawah berikut.

Tabel 1. Kriteria Sinyal Yang Dihasilkan

\begin{tabular}{lc}
\hline Kualitas & Range Kuat Sinyal $(\mathrm{dBm})$ \\
\hline Excellent & $>-61$ \\
Good & $-75--61$ \\
Fair & $-85--75$ \\
Poor & $-97--75$ \\
Very Poor & $<-97$ \\
\hline
\end{tabular}

Evaluasi dilakukan dengan cara menganalisis hasil pengujian tersebut, untuk kemudian dilakukan

\section{Grafik Hasil Dari Inssider}

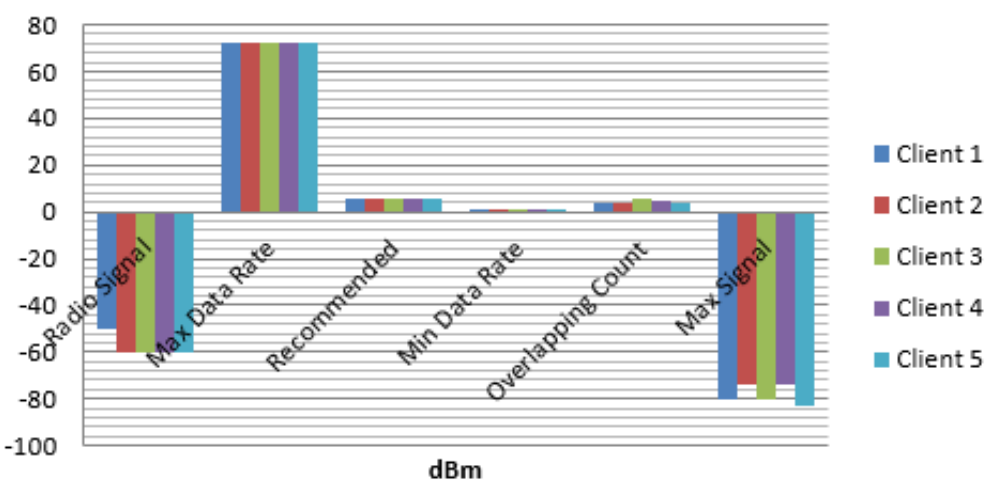

Gambar 8. Grafik Hasil Dari Inssider yaitu:

Dari grafik di atas di dapatkan kesimpulan dan saran, Dalam penelitian ini

a. Pengujian transmitter berdasarkan parameter, tinggi dan propagasinya terhadap receiver berdasarkan parameter jarak dan RSSI.

b. Membandingkan hasil pengujian berdasarkan parameter posisi access point sebenarnyadengan posisi access point hasil optimisasi menggunakan interferensi dengan metodesimulatedannealing.

c. Perubahan jarak access point dengan receiver memberikan pengaruh yang besar terhadap nilai RSSI yang diterima oleh receiver.

d. Terjadi peningkatan kekuatan sinyal yang cukup signifikan terhadap penempatan

posisi access point dengan kondisi receiver dan penghambat yang ada pada ruangan.

e. Jarak dan hambatan memberikan pengaruh yang besar terhadap nilai RSSI yang di hasilkan. 


\section{SIMPULAN}

Berdasarkan uraian hasil pembahasan sebelumnya dapat disimpulkan bahwa Metode yang dikembangkan dalam penelitian ini memberikan hasil optimisasi yang lebih baik pada propagasi LOS untuk gedung 1 lantai 4 AMIK TUNAS BANGSA Pematangsiantar menghasilkan presentase coverage area terbaik. Dengan hasil RSSI di antara $-50 \mathrm{dBm}$ s/d $-60 \mathrm{dBm}$ yang masuk dalam kategori kekuatan sinyal Excellent.

\section{DAFTAR PUSTAKA}

[1]. Nila F.P., “Optimasi Penempatan Posisi Access Point Pada Jaringan Wi-fi Menggunakan Metode SimulatedAnnealing”, Citec Jurnal, ISSN : 23545771, 2015

[2]. Sari, I. P., Santoso, T., Siswandari, N. A., 2010. “Optimisasi Penataan Sistem Wi-Fi di PENSITS dengan Menggunakan Metode Monte Carlo", Seminar Proyek Akhir Jurusan Telekomunikasi, Politeknik Elektronika Negeri Surabaya - ITS, Surabaya.

[3]. Kartika, K. P., Santoso, T. B., Siswandari, N. A., 2010, “Optimisasi Penataan Sistem Wi-Fi di PENS-ITS dengan Menggunakan Metode Algoritma Genetika", Seminar Proyek Akhir Jurusan Telekomunikasi, Politeknik Elektronika Negeri Surabaya - ITS, Surabay

[4]. Sari, I. P., Santoso, T., Siswandari, N. A., "Optimisasi Penataan Sistem Wi-Fi di PENSITS dengan Menggunakan Metode Monte Carlo", Seminar Proyek Akhir Jurusan Telekomunikasi, Politeknik Elektronika Negeri Surabaya - ITS, Surabaya, 2010.

[5]. Kouhbor, S., Ugon, J., Kruger, A., Rubinov, A., “Optimal Placementof Access Point in WLAN Basedon a New Algorithm, International Conferenceon Mobile Business", ICMB 2005, Sydney, Australia, 11-13 Juli 2005.

[6]. Rizal, J., 2007, “Optimisasi Pada TravelingSalesman Problem (TSP) dengan Pendekatan Simulasi Annealing", Jurnal Gradien, Vol 3, No 2, Hal 286-290.

[7]. Zheng, X., Bao, G., Fu, R., Pahlavan, K., 2012, “The performance of Simulated Annealing Algorithmsfor WiFi Localization using Google Indoor Map", Prosiding IEEE Vehicular Technology Conference, Quebec City, Canada, 3-6 September 2012.

[8]. Sandeep, A. R., Shreyas, Y., Seth, S., Agarwal, R., Sadashivappa, G., "Wireless Network VisualizationandIndoorEmpiricalPropagation Model for a Campus WI-FI Network", World AcademyofScience, Engineering and Technology, Vol 42, Hal 730-734.2008. 